\title{
Laminin-332 promotes the invasion of oesophageal squamous cell carcinoma via PI3K activation
}

\author{
Y Baba', ${ }^{1,2}$ K-i lyama', K Hirashima', Y Nagai', N Yoshida', N Hayashi', N Miyanari' and H Baba*,I \\ 'Department of Gastroenterological Surgery, Graduate School of Medical Sciences, Kumamoto University I- I I Honjo, Kumamoto City, Kumamoto \\ 860-8556, Japan; '2Department of Surgical Pathology, Kumamoto University Hospital, I- I - I Honjo, Kumamoto City, Kumamoto 860-8556, Japan
}

Laminin-332 is major component of epithelial basement membrane, and has an important role in cell migration and tumour invasion. Recently, the phosphatidylinositol 3-kinase (PI3K) activation induced by laminin-332 during carcinogenesis or tumour invasion has been highlighted in skin squamous cell carcinoma. The expression of laminin-332 in 126 resected oesophageal squamous cell carcinoma (ESCC) specimens was immunohistochemically examined to determine its associations with the clinicopathological characteristics, and the effect of laminin-332 on the invasiveness and the PI3K activation was assessed by in vitro experiments using ESCC cell lines (ESCCs). Sections with immunostaining signals in $>30 \%$ cancer cells, which were observed in 55 of 126 cases, were judged to be positive for laminin-332. The positivity was significantly correlated with pTNM stage and poor prognosis. Inactivation of the PI3K pathway by laminin-332 blocking antibody suppressed the invasiveness of TE8 cell line, which secreted laminin-332 at high level and had high PI3K activity. The addition of the purified laminin-332 activated the PI3K pathway and increased the invasiveness of TEII cell line, which secreted laminin-332 at lower level and had low PI3K activity. The deactivation of PI3K pathway using the PI3K inhibitor decreased the invasiveness of ESCCs and the secretion of laminin-332 in vitro. The expression of laminin-332 was one of the prognostic factors of ESCC. Laminin-332 could provide the autocrine positive-feedback loop through PI3K activation, contributing the invasive ability. Therefore, the inhibitor of PI3K pathway might be useful as the anticancer therapies for ESCC.

British Journal of Cancer (2008) 98, 974-980. doi:I 0.1038/sj.bjc.6604252 www.bjcancer.com

Published online 19 February 2008

(c) 2008 Cancer Research UK

Keywords: laminin-332; PI3K pathway; oesophageal cancer, basement membrane; prognostic factor

Laminins are the best-known member of a family of the basement membrane (BM) protein, and they are important in cell growth, differentiation, adhesion and migration. The laminin molecule is a cross-shaped heterotrimer consisting of one heavy $\alpha$ chain and two light chains, $\beta$ and $\gamma$ chains (Timpl, 1989; Beck et al, 1990; Yurchenco and Schittny, 1990; Engle, 1992). To date, 16 laminin isoforms with different contributions of $\alpha 1-\alpha 5, \beta 1-\beta 3, \gamma 1-\gamma 3$ chains have been identified (Miyazaki, 2006; Marinkovich, 2007). Each laminin chain contains many functional domains, allowing the laminins to interact with various molecules in the extracellular matrix. For example, laminin $\alpha$ chains $(\alpha 1-\alpha 5)$ contain large globular $\mathrm{G}$ domains in their $\mathrm{C}$ terminus, which is divided into five homologous subdomains (G1-G5). The G domain is thought to be a major site of interaction with specific receptors on the cell surface, including integrins, syndecans and $\alpha$-dystroglycan. The $\mathrm{N}$-terminal region of the three chains contains functional domains that are mainly involved in matrix assembly (Timpl, 1989; Beck et al, 1990; Yurchenco and Schittny, 1990; Engle, 1992).

Laminin-332 (previously known as laminin-5), which comprises $\alpha 3, \beta 3$ and $\gamma 2$ chains, is a major component of epithelial BM, acts as an adhesion substrate for the epithelial cells and regulates epithelial cell migration during epithelial regeneration and repair

*Correspondence: Dr H Baba;

E-mail: hdobaba@kumamoto-u.ac.jp

Received 19 November 2007; revised 15 January 2008; accepted 16 January 2008; published online 19 February 2008 processes in normal tissues (Carter et al, 1991; Rousselle et al, 1991; Ryan et al, 1996). Laminin-332 interacts with two major epithelial integrin $\alpha 3 \beta 1$ and $\alpha 6 \beta 4$, and promotes the formation of two separate types of attachment structure, focal adhesion and stable anchoring contacts (Carter et al, 1990). In several types of carcinomas, laminin-332 has been reported to be highly expressed and to correlate well with poor patient prognosis (Pyke et al, 1995; Soini et al, 1996; Koshikawa et al, 1999; Matta et al, 1999; Ono et al, 1999; Yamamoto et al, 2001; Fukai et al, 2005). Laminin-332 is known to support cellular survival, proliferation and migration by activating many signal mediators through the ligation with $\alpha 3 \beta 1$ and $\alpha 6 \beta 4$ integrin, and to have important roles in tumour invasion and metastasis (Nguyen et al, 2000; Kariya and Miyazaki, 2004; Nikolopoulos et al, 2005). Particularly, the phosphatidylinositol 3-kinase (PI3K) activation induced by laminin-332 during carcinogenesis or tumour invasion has been highlighted (Marinkovich, 2007; Waterman et al, 2007). Marinkovich has demonstrated that the interaction of laminin-332 with $\alpha 6 \beta 4$ integrin and epidermal growth factor receptor (EGFR) was involved in promoting the PI3K activation and tumour invasion (Marinkovich, 2007).

Oesophageal squamous cell carcinoma (ESCC) is one of the most aggressive malignant tumours, and the prognosis of ESCC is worse than that of other digestive tract carcinomas (Enzinger and Mayer, 2003). As to ESCC, there are two papers demonstrating that the immunohistochemically increased cytoplasmic expression of laminin-332 is correlated with poor prognosis (Yamamoto et al, 2001; Fukai et al, 2005). However, to our knowledge, there are no 
data showing the relationship between laminin-332 and cancer cell invasiveness, using oesophageal squamous cancer cell lines (ESCCs).

The aims of this study are (1) to investigate the immunohistochemical expression of laminin-332 in ESCC and to evaluate the relationships between the clinicopathological characteristics and survival, and (2) to examine the biological role and the signalling pathway of laminin-332 using ESCCs.

\section{MATERIALS AND METHODS}

\section{Patients}

The present study involved 126 consecutive patients with ESCC who underwent the curative surgical resection at Kumamoto University Hospital from January 1997 to December 2006. All of these patients underwent an oesophagectomy with lymph node dissection. None of these patients underwent endoscopic mucosal resection, palliative resection, preoperative chemotherapy or radiotherapy, and none of them had synchronous or metachronous multiple cancers in other organs. Clinical data, including age, sex, tumour location, lymph node metastasis, $\mathrm{T}$ classification (Sobin and Wittekind, 2002), TNM stage (Sobin and Wittekind, 2002) and histological grading (Hamilton and Aaltonen, 2000), were available for all 126 patients. Patients were periodically (every 1-3 months) examined on an outpatient basis to make sure they did not have disease recurrence. The mean follow-up period for the 126 patients was 29.6 months (range, 1-110 months). Informed consent for the research was obtained from each patient. The study design was approved by the ethic review board of our university.

\section{Immunohistochemistry}

Sections of $5 \mu \mathrm{m}$ in thickness were dewaxed in xylene and rehydrated in ethanol and then heated to $132^{\circ} \mathrm{C}$ in an autoclave for $5 \mathrm{~min}$ in $10 \mathrm{nmoll}^{-1}$ citrate buffer ( $\mathrm{PH} \mathrm{6.3)}$. The endogenous peroxidase activity was suppressed by a solution of $3 \%$ hydrogen peroxide in methanol for $60 \mathrm{~min}$. The sections were immersed in $5 \%$ normal horse serum in PBS for $30 \mathrm{~min}$, covered with mouse anti-laminin $\gamma 2$ chain $(1: 200$, Chemicon, Billerica, USA), and incubated overnight at $4{ }^{\circ} \mathrm{C}$. Negative controls were stained with PBS and normal mouse IgG instead of the primary antibody. Immunoreactions were performed using a Vecstatin peroxidase $\mathrm{ABC}$ kit (Vector Laboratories, Peterborough, UK). The antigenic sites were demonstrated by reacting the sections with a mixture of 0.05\% 3,3-diaminobenzidine tetrahydrochloride (Dojindo Chemicals, Dojindo Laboratories, Kumamoto, Japan) in $0.05 \% \mathrm{moll}^{-1}$ Tris- $\mathrm{HCl}$ buffer, $\mathrm{pH} 7.6$, containing $0.01 \% \mathrm{H} 2 \mathrm{O} 2$ for $5 \mathrm{~min}$. The nuclei were stained with haematoxyline.

Sections with immunohistochemical staining in $>30 \%$ of carcinoma cells at the invasive front were judged to be positive for laminin-332 as with the previous reports (Yamamoto et al, 2001; Fukai et al, 2005). The staining assessment was independently carried out by two of the authors (KI and YB) without any knowledge of either the clinical or survival data.

\section{Cell culture}

ESCCs were obtained from Cell Resource Center for Biomedical Research, Tohoku University, Japan. Cell cultures were grown in recommended medium with $10 \%$ fetal bovine serum (FBS) and incubated in $5 \% \mathrm{CO}_{2}$ at $37^{\circ} \mathrm{C}$.

\section{Antibodies and other reagents}

Antibodies for western blot analysis were as follows: rabbit antiphospho Akt, rabbit anti-Akt (Cell Signaling Technology, Danvers, USA), mouse anti-laminin $\gamma 2$ chain (Chemicon), mouse anti-epidermal growth factor receptor (ZYMED Laboratories, San Francisco, USA), mouse anti-integrin $\beta 4$ (Santa Cruz Biotechnology, Santa Cruz, USA). Anti-laminin $\gamma 2$ antibody (Chemicon) was used as the blocking antibody as with previous article (Decline and Rousselle, 2001). The purified human laminin-332 was purchased from Biodesign Internatinal, and the PI3K inhibitor Wortmannin was purchased from Santa Cruz Biotechnology.

\section{Western blot analysis}

Cultured cells were solubilised with the lysis buffer (Tris-HCl (pH7.4). $25 \mathrm{~mm}, \mathrm{NaCl} 100 \mathrm{~mm}$, EDTA $2 \mathrm{~mm}$, TritonX $1 \%$ with $10 \mu \mathrm{g} \mathrm{ml}^{-1}$ Aprotinin, $10 \mu \mathrm{g} \mathrm{ml}^{-1}$ Leupeptin, $1 \mathrm{mM} \mathrm{Na}_{3} \mathrm{VO}_{4}, 1 \mathrm{~mm}$ PMSF). To evaluate the secreted laminin-332 in the cell culture medium, each cell line was plated at $1 \times 10^{6}$ cells per $100-\mathrm{mm}$ culture dish in serum-free medium. Conditioned medium was collected at $24 \mathrm{~h} .10 \mu \mathrm{g}$ of each protein sample was mixed with $4 \times$ sample buffer including $10 \% \beta$-mercaptoethanol and boiled $5 \mathrm{~min}$. Next, equal amount of samples were separated on $7.5 \%$ (for the reduced laminin-332), $6.0 \%$ (for the non-reduced laminin-332) or $12 \%$ (for others) SDS-polyacrylamide gels and transferred to PVDF membranes. The membranes were probed with each primary antibody overnight at room temperature, followed by a 1:1000 dilution of peroxidase-conjugated IgG antibody (Sigma, St Louis, USA). Detection was accomplished with an ECL reagent (Amersham, Buckinghamshire, UK).

To evaluate the relationship between the secretion of laminin332 and the PI3K pathway, the confluent cells were incubated with the PI3K inhibitor (Wortmannin) at different concentration for $24 \mathrm{~h}$, and the culture medium was collected. Equal amount of samples were separated on $7.5 \%$ SDS-polyacrylamide gel and transferred to PVDF membranes.

\section{Cell-invasion assay}

In vitro cell invasion assay was conducted using Biocoat Matrgel Invasion Chambers (BD Biosciences Discovery Labware, Franklin, USA) according to the manufacturer's protocols. After detaching the cells in $0.25 \%$ trypsin and counting, cells were diluted to 100000 cells per $\mathrm{ml}$ in medium counting $0.5 \%$ FBS. A total of $500 \mu \mathrm{l}$ of cells were then placed in quintuple in the top chamber of the insert above medium counting $10 \% \mathrm{FBS}$, and were incubated in $37^{\circ} \mathrm{C}, 5 \%$ $\mathrm{CO}_{2}$ for $22 \mathrm{~h}$. Next, the cells on the upper surface of the membrane were removed with a cotton swab, and the migrated cells on the underside of the membrane were fixed and stained using toluidine blue and counted in five random fields at $\times 200$ magnification.

To examine the effects of the purified laminin-332, anti-laminin332 blocking antibody and the PI3K inhibitor (Wortmannin) on the invasiveness of ESCCs, the purified laminin-332 $\left(0.5 \mu \mathrm{g} \mathrm{ml}^{-1}\right)$, anti-laminin-332 blocking antibody $\left(40 \mu \mathrm{g} \mathrm{ml}^{-1}\right)$ or the PI3K inhibitor (Wortmannin; $100 \mathrm{nM}$ ) was added into the top chamber. As controls, the purified albumin $\left(0.5 \mu \mathrm{g} \mathrm{ml}^{-1}\right)$ or anti-IgG antibody $\left(40 \mu \mathrm{g} \mathrm{ml}^{-1}\right)$ was used.

\section{Statistical analysis}

Laminin-332 expression in ESCC was assessed to identify any associations with clinicopathological parameters using $\chi^{2}$ twotailed test or Fisher's exact test. The disease-free survival and overall cancer-specific survival curves were constructed using the Kaplan-Meier method, and the log-rank test was used to evaluate the statistical significance of the differences. The prognostic significance of clinicopathological parameters was determined using univariate and multivariate Cox regression analysis. In vitro assay, a statistical analysis was performed using Mann-Whitney's $U$-test for unpaired samples. Statistical analysis was performed using SPSS software (version 13 for Windows; SPSS, Chicago, IL, 
USA). A two-sided significance level of $P<0.05$ was used for all statistical analyses.

\section{RESULTS}

\section{Immunohistochemical expression of laminin-332 in oesophageal squamous cell carcinomas}

In normal oesophageal epithelium, laminin-332 $\gamma 2$ chain was stained weakly in the cytoplasm of epithelial cells near basal layer. (Figure 1A and B) In some cancer tissues, the cytoplasm of cancer cells was stained for laminin-332 $\gamma 2$ chain at levels much stronger than those in normal BM. Sections with immunostaining signals in $>30 \%$ of carcinoma cells, which were observed in 55 (44\%) cases, were judged to be positive for laminin-332 $\gamma 2$ chain expression (Figure $1 \mathrm{C}$ and D).

The relationships between laminin-332 expression and clinicopathological characteristics are summarised in Table 1 . The expression of laminin-332 was significantly correlated to TNM stage $(P=0.036)$. The patients with laminin-332-positive ESCC had a higher tendency to have lymph node metastasis and deep invasion than those with negative; however, the differences were not statistically significant ( $P=0.14$ and $P=0.15$, respectively). On the other hand, there were no significant relationships between laminin332 expression and age, sex, tumour location and histological grading.

Patients with laminin-332-positive tumours had a significantly shorter disease-free survival and overall cancer-specific survival than patients with laminin-332 negative tumours $(P=0.0139$ and $P=0.0345$, respectively; Figure 2). In univariate analysis, the significant prognostic factors for predicting both the disease-free survival and overall cancer-specific survival were histological grading, T classification, TNM stage, lymph node metastasis and laminin-332 expression. In multivariate analysis, laminin-332 expression was the independent prognostic factors for predicting the disease-free survival, but not for the overall cancer-specific survival (Table 2).
Table I The relationship between clinicopathological characteristics and expression of laminin 332

\begin{tabular}{|c|c|c|c|c|}
\hline Characteristic & $\begin{array}{c}\text { Total } \\
(n=126)\end{array}$ & $\begin{array}{c}\text { Negative } \\
(n=71)\end{array}$ & $\begin{array}{l}\text { Positive } \\
(n=55)\end{array}$ & $P$-value \\
\hline Mean age & & $63.7 \pm 5.3$ & $62.8 \pm 4.9$ & \\
\hline Sex & & & & 0.81 \\
\hline Male & 106 & 59 & 47 & \\
\hline Female & 20 & 12 & 8 & \\
\hline Tumour location & & & & 0.62 \\
\hline Upper & 27 & 13 & 14 & \\
\hline Middle & 57 & 33 & 24 & \\
\hline Lower & 42 & 25 & 17 & \\
\hline $\begin{array}{l}\text { Histological } \\
\text { grading }\end{array}$ & & & & 0.75 \\
\hline Well & 51 & 29 & 22 & \\
\hline Moderate & 48 & 26 & 22 & \\
\hline Poorly & 27 & 16 & 11 & \\
\hline T classification & & & & 0.15 \\
\hline $\mathrm{TI}$ & 63 & 39 & 24 & \\
\hline $\mathrm{T} 2$ & 24 & 15 & 9 & \\
\hline T3 & 39 & 17 & 22 & \\
\hline$N$ status & & & & 0.14 \\
\hline No & 62 & 39 & 23 & \\
\hline $\mathrm{NI}$ & 64 & 32 & 32 & \\
\hline Stage & & & & 0.036 \\
\hline 1 & 47 & 30 & 16 & \\
\hline$\| \mathrm{A}$ & 15 & 9 & 6 & \\
\hline$\| B$ & 31 & 20 & 11 & \\
\hline III & 33 & 12 & 22 & \\
\hline
\end{tabular}

$\mathrm{N}$ status indicates lymph node metastasis status. $P$-values were calculated by using $\chi^{2}$ and Fisher's exact tests.
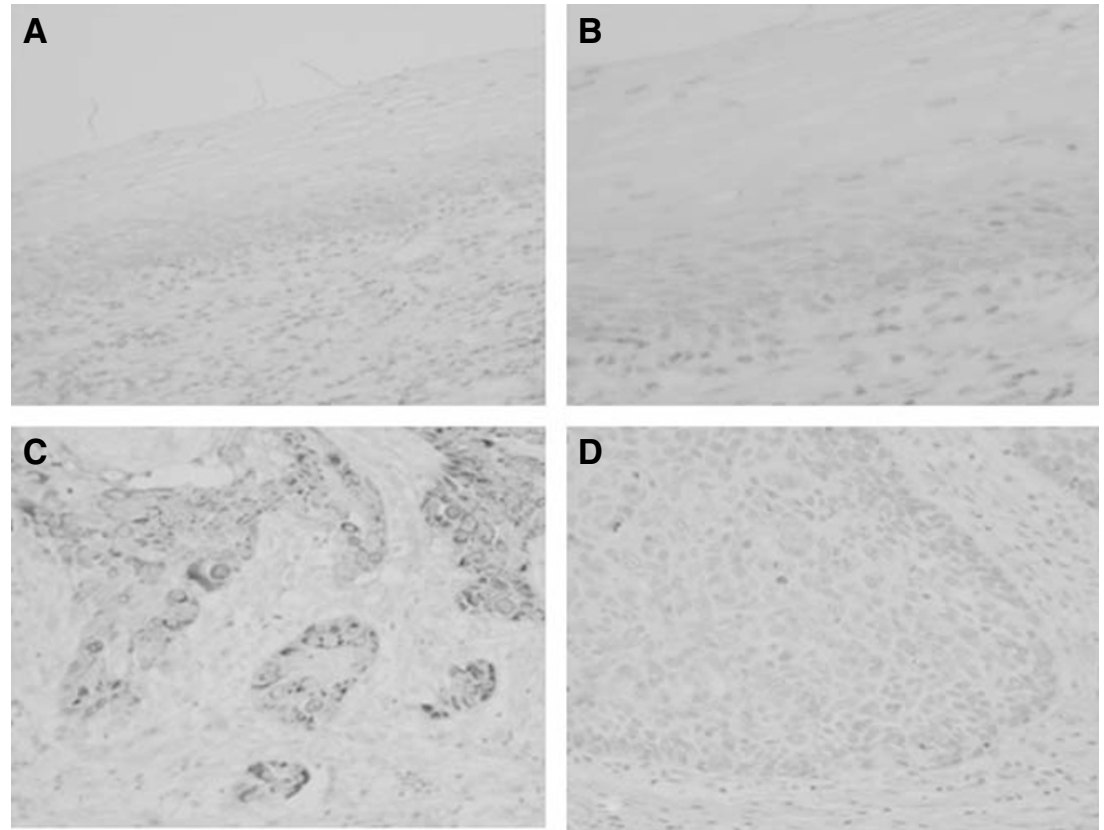

Figure I Immunohistochemical staining of laminin-332. Original magnification: $\times 200($ A,C,D $) \times 400$ (B). (A, B) Expression of laminin-332 in normal oesophageal epithelium. Laminin-332 is expressed faintly in the cytoplasm of epithelial cells in the basal layer. (C) Positive staining of laminin-332 of ESCC is indicated. Laminin-332 is clearly shown in the cytoplasm of ESCC. (D) Negative staining of laminin-332 of ESCC is indicated. 

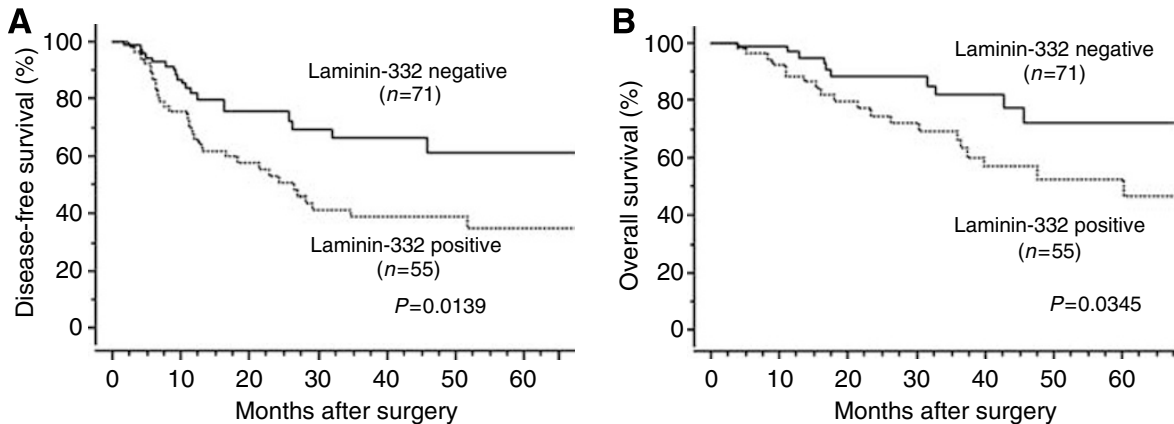

Figure 2 (A) Disease-free survival in relation to laminin-332 expression status of ESCC patients. (B) Overall cancer-specific survival in relation to laminin332 expression status.

Table 2 Multivariate analysis of disease-free survival and overall cancerspecific survival in oesophageal squamous cell carcinoma

\begin{tabular}{|c|c|c|c|c|c|c|c|}
\hline \multirow[b]{2}{*}{ Characteristic } & \multirow[b]{2}{*}{ No. } & \multicolumn{3}{|c|}{ Disease-free survival } & \multicolumn{3}{|c|}{ Overall survival } \\
\hline & & HR & $95 \% \mathrm{Cl}$ & $P$ & HR & $95 \% \mathrm{Cl}$ & $P$ \\
\hline \multicolumn{8}{|l|}{$N$ status } \\
\hline No (reference) & 62 & 1.00 & & & 1.00 & & \\
\hline $\mathrm{NI}<$ & 64 & 4.75 & $1.67-13.5$ & 0.004 & 7.75 & $1.79-24.9$ & 0.006 \\
\hline \multicolumn{8}{|l|}{ Histological grading } \\
\hline Well (reference) & 51 & 1.00 & & & 1.00 & & \\
\hline Moderate, poorly & 75 & 2.67 & $1.39-5.14$ & 0.012 & 2.34 & $1.03-5.30$ & 0.038 \\
\hline \multicolumn{8}{|l|}{ Laminin 332} \\
\hline Negative (reference) & 71 & 1.00 & & & 1.00 & & \\
\hline Positive & 55 & 2.01 & $1.18-2.64$ & 0.043 & 1.93 & $0.97-3.42$ & 0.062 \\
\hline
\end{tabular}

\section{Expression of laminin-332 in oesophageal cancer cell lines}

A western blot analysis showed that all five ESCC cell lines (TE1, TE8, TE9, TE10, TE11) secreted laminin-332 $\gamma_{2}$ chain into the conditioned medium, but the secreted level of TE11 was lowest (Figure 3A). In the reduced sample (upper panel), the $155-\mathrm{kDa}$ band revealed the uncleaved laminin-332 $\gamma 2$ chain, whereas the $105-\mathrm{kDa}$ band revealed the cleaved laminin-332 $\gamma_{2}$ chain. In the nonreduced sample (lower panel), the upper band revealed the laminin-332 heterotrimer including the uncleaved laminin-332 $\gamma 2$ chain, whereas the lower band revealed the laminin-332 heterotrimer including the cleaved laminin-332 $\gamma 2$ chain.

\section{Expression of EGFR and integrin $\beta 4$ in oesophageal cancer} cell lines

All five ESCCs expressed EGFR at the protein level. But the band intensity was different between each ESCCs, and showed expression at the highest level in TE8 and at the lowest level in TE1 (Figure 3B). All five ESCCs expressed integrin $\beta 4$ at the protein level at the approximately same level (Figure 3B).

\section{PI3K activation in oesophageal cancer cell lines}

We examined the activity of PI3K pathway by using the phosphorylated Akt (p-Akt) antibody by western blot analysis. The band intensity of p-Akt showed expression at higher level in TE8, TE9 and TE10 than in TE1, TE11 (Figure 3C).

\section{Laminin-332-blocking antibody inhibit PI3K activity and} invasion in TE10

The effect of the laminin-332-blocking antibody on PI3K pathway was tested in vitro using TE10, which secreted laminin-332 at the highest level among cell lines and had high PI3K activity in vitro. After the incubation with the laminin-332-blocking antibodies at different concentration for $24 \mathrm{~h}$, the cells were solubilised. The laminin-332-blocking antibody suppressed the activation of PI3K pathway at the concentration of $>40 \mu \mathrm{g} \mathrm{ml}^{-1}$ (Figure $4 \mathrm{~A}$ ). The similar results were achieved by using TE8 and TE9 (data not shown). Next, we investigated whether the laminin-332-blocking antibody have an effect on the invasiveness of TE10 in vitro using the Matrigel-coated invasion chamber. The number of invaded cells decreased to an approximately half with the laminin-332blocking antibody $\left(40 \mu \mathrm{g} \mathrm{ml}^{-1}\right)$ by comparison with non-treatment or the IgG antibody $\left(40 \mu \mathrm{g} \mathrm{ml}^{-1}\right)$. The PI3K inhibitor (Wortmannin; $100 \mathrm{~nm}$ ) decreased the number of invaded cells to an approximately quarter by comparison with non-treatment (Figure 4B).

\section{Laminin-332 promotes invasion via PI3K activation in TE11}

The effect of the purified laminin-332 on PI3K pathway was examined in vitro using TE11, which secreted laminin-332 at the lowest level. After the incubation with the purified laminin-332 at different concentration for $6 \mathrm{~h}$, the cells were solubilised. The laminin-332 activated the PI3K pathway at the proportion to the concentration of laminin-332 (Figure 5A). The number of invaded cells increased significantly with the purified laminin-332 $\left(0.5 \mu \mathrm{g} \mathrm{ml}^{-1}\right)$ by comparison with non-treatment or controlpurified albumin $\left(0.5 \mu \mathrm{g} \mathrm{ml}^{-1}\right)$; however the addition of the PI3K inhibitor (Wortmannin;100 nM) decreased the number of invaded cells significantly (Figure 5B).

\section{Effect of PI3K inhibitor on the secretion of laminin-332 in vitro}

The relationship between the secretion of laminin-332 and PI3K pathway was also investigated. The PI3K inhibitor (Wortmannin) decremented the activity of PI3K pathway in a dose-dependent manner, and the amount of the secreted laminin-332 into the medium decreased in proportion to the activity of PI3K pathway (Figure 6).

\section{DISCUSSION}

In the present study, the laminin-332 expression in cancer cells at the invasive front was seen in $44 \%$ of ESCC, and ESCC patients 

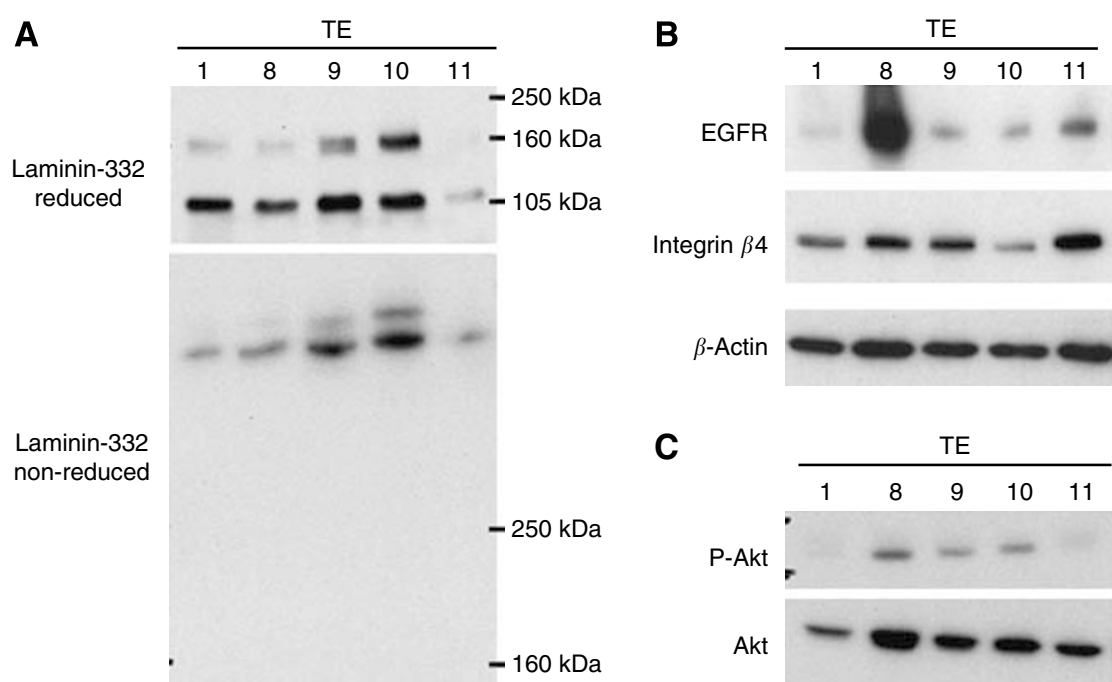

Figure 3 (A) Expression of laminin-332 in the conditioned medium of each ESCCs. All five ESCCs (TEI, 8, 9, 10, II) secreted laminin-332, but the secreted level of TEII is low. In the reduced medium (upper panel), the I55-kD band shows the un-cleaved laminin-332 $\gamma 2$ chain, and the I05-kD band shows the cleaved laminin-332 $\gamma 2$ chain. In the non-reduced medium (lower panel), the upper band shows the laminin-332 heterotrimer including the uncleaved laminin-332 $\gamma 2$ chain, and the lower band shows the laminin-332 heterotrimer including the cleaved laminin-332 $\gamma 2$ chain. (B) Expression of EGFR and Integrin $\beta 4$ in each ESCCs. All five ESCCs express EGFR. The band intensity shows the expression at the highest level in TE8 and at the lowest level in TEI. All five ESCCs express integrin $\beta 4$ approximately at the same levels. (C) The activity of PI3K pathway was evaluated by Western blot analysis using the p-Akt antibody. The band intensity of p-Akt shows expression at higher level in TE8, TE9 and TEIO than in TEI, TEII.

A
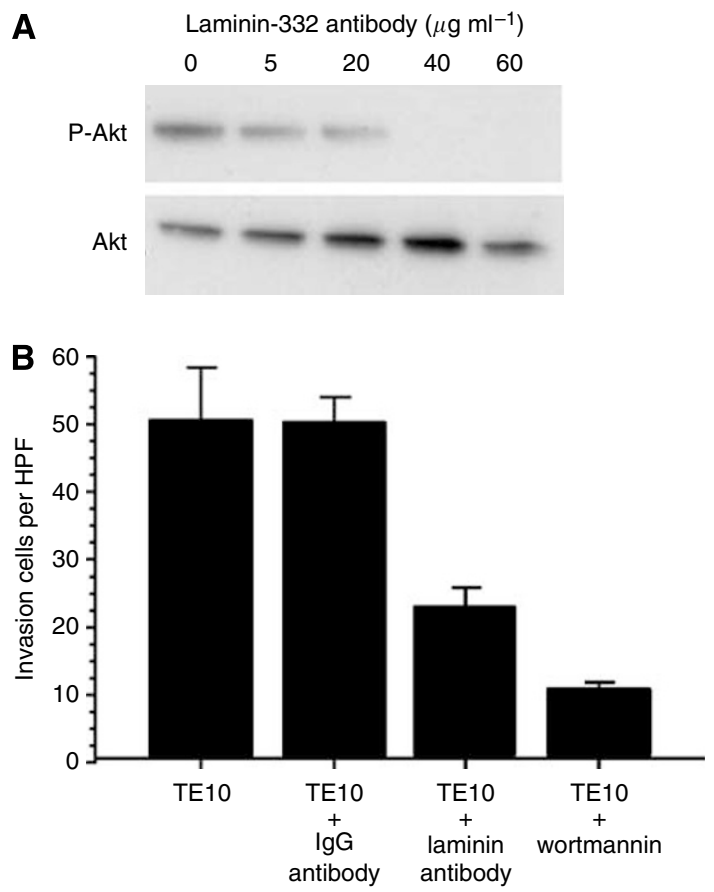

Figure 4 (A) The effect of the laminin-332 blocking antibody at different concentration on PI3K pathway in TEIO cell line. The laminin-332 blocking antibody suppresses the activation of PI3K pathway at the concentration of $>40 \mu \mathrm{g} / \mathrm{ml}$. (B) The effect of the laminin-332 blocking antibody on the invasiveness of TEIO. The number of invaded cells decreases to an approximately half with the laminin-332 blocking antibody $(40 \mu \mathrm{g} / \mathrm{ml})$ by comparison with non-treatment or control lgG antibody $(40 \mu \mathrm{g} / \mathrm{ml})$. The PI3K inhibitor (Wortmannin; I00 nM) decreased to an approximately quarter by comparison with non-treatment.

with its positivity had poorer prognosis than patients with its negativity. This result was consistent with previous reports about ESCC (Yamamoto et al, 2001; Fukai et al, 2005) and suggested that
A
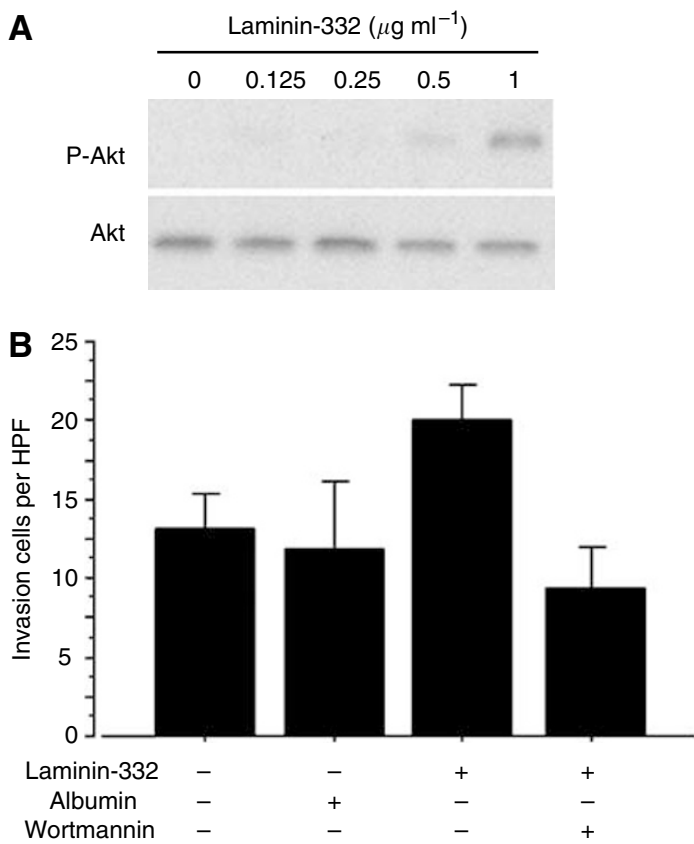

Figure 5 (A) The effect of the purified laminin-332 at different concentration on PI3K pathway in TEII cell line. The addition of the purified laminin-332 activated the PI3K pathway at the concentration of $>0.5 \mu \mathrm{g} / \mathrm{ml}$. (B) The effect of the purified laminin-332 on the invasiveness of TEI I cell line. The number of invaded cells increases with additional laminin-332 $(0.5 \mu \mathrm{g} / \mathrm{ml})$ by comparison with non-treatment or control Albumin $(0.5 \mu \mathrm{g} / \mathrm{ml})$. However, the number of invaded cells decreased with both additional laminin-332 $(0.5 \mu \mathrm{g} / \mathrm{ml})$ and Wortomannin ( $100 \mathrm{~nm})$.

laminin-332 at the invasive front of ESCC might have an important role in the process of tumour invasion.

Laminin-332 has been reported to have potent cell migrationpromoting activity. Miyazaki and co-workers showed that both 

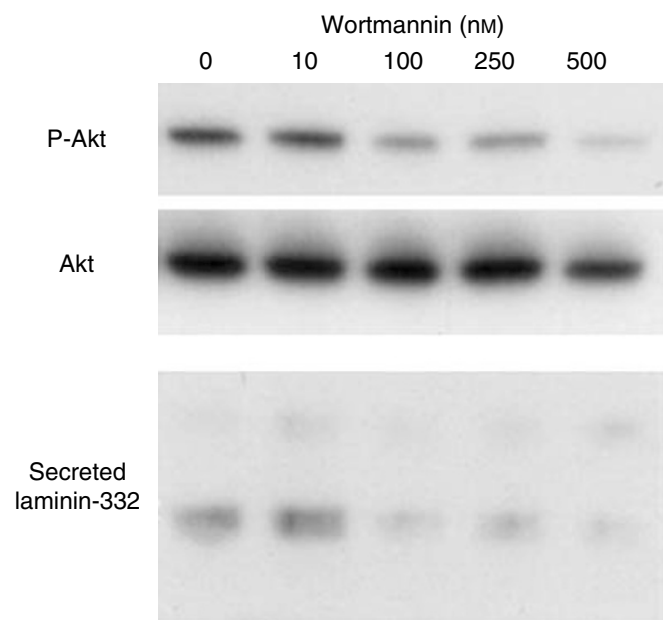

Figure 6 The relationship between the secretion of laminin-332 and PI3K pathway in TEIO cell line. The PI3K inhibitor (Wortmannin) decreases the activity of PI3K pathway in a dose-dependent manner, and the amount of the secreted laminin-332 into the medium decrease in proportion to the activity of PI3K pathway.

soluble and deposited laminin-332 could stimulate the migration of human normal epithelial cells and cancer cells in vitro (Miyazaki et al, 1993; Kariya and Miyazaki, 2004). Laminin-332 has been reported to interact with integrin $\alpha 3 \beta 1$ or $\alpha 6 \beta 4$ and activate many signal mediators such as $\mathrm{PI} 3 \mathrm{~K}$, focal adhesion kinase, protein kinase $\mathrm{C}, \mathrm{Rac}, \mathrm{ERK}, \mathrm{JNK}$ and nuclear factor $\kappa \mathrm{B}$, leading to enhanced cell migration and invasion (Nguyen et al, 2000; Kariya and Miyazaki, 2004; Nikolopoulos et al, 2005). In particular, the importance of PI3K activation induced by laminin-332 during carcinogenesis or tumour invasion has been recently suggested (Marinkovich, 2007; Waterman et al, 2007). Waterman and coworkers demonstrated that by in vivo model of human skin keratinocytes, the binding of laminin-332 to $\alpha 6 \beta 4$ integrin associated and drove tumorgenesis and invasion thorough PI3K activation in skin squamous cell carcinoma (Waterman et al, 2007). Furthermore, the interaction between laminin-332 $\gamma 2$ chain III domain and EGFR has been suggested to have a role in PI3K activation via the action of FYN kinase (Schenk et al, 2003; Guo et al, 2006; Marinkovich, 2007). Briefly, the interaction of laminin332 with $\alpha 6 \beta 4$ integrin and EGFR is involved in promoting PI3K activation and tumour invasion. To our knowledge, as there has been no article showing the relationship between laminin-332 and PI3K activation in ESCC, we focused on the relationship between the PI3K activation and invasiveness of ESCCs in the current study.

PI3K is a major signalling component downstream of growth factor receptor tyrosine kinase, and the PI3K pathway regulates various cellular processes, such as proliferation, growth, apoptosis and cytoskeleton rearrangement (Cantley, 2002). The aberrant activation of the PI3K pathway has been widely implicated in several types of carcinomas (Vivanco and Sawyers, 2002; Fresno Vara et al, 2004). In our in vitro study, the PI3K activity was assessed at higher level in TE8, TE9 and TE10 than in TE1 and TE11. As TE8, TE9 and TE10 secreted laminin-332 at higher level and also expressed EGFR and integrin $\beta 4$, which were interacted with laminin-332, and TE11 secreted laminin-332 at very low level, the levels of PI3K activity in these ESCCs were understandable. Similarly in TE1, as this cell line expressed EGFR at very low level, the secreted laminin-332 might be unable to induce intracellular signal transduction in vitro. In fact, the addition of the purified laminin-332 did not activate the PI3K pathway in TE1 in vitro (data not shown). The laminin-332-blocking antibody deactivated the PI3K pathway, leading to suppress the invasiveness of TE10, which secreted laminin-332 at high level and had high PI3K activity. On the contrary, the addition of the purified laminin-332 activated the PI3K pathway, leading to increase the invasiveness of TE11, which secreted laminin-332 at lower level and had weak PI3K activity; however, the accession of the PI3K inhibitor decrease the invasiveness. These results suggest that laminin-332 could enhance the invasiveness of ESCCs through the PI3K activation.

In our in vitro study, the deactivation of PI3K pathway using PI3K inhibitor decreased the secretion of laminin-332, hence the PI3K activation was considered to be required for the secretion of laminin-332. Laminin-332 might provide the autocrine positivefeedback loop via the PI3K activation, contributing the invasive ability. These results suggest that the inhibitor of PI3K pathway could be useful as the anticancer therapy for ESCC (Luo et al, 2003). As to the downstream of PI3K pathway, further studies are needed.

In conclusion, the increased laminin-332 immunoreactivity is one of the prognostic factors of ESCC. Laminin-332 could provide the autocrine positive-feedback loop through the PI3K activation, contributing the invasive ability, hence the inhibitor of PI3K pathway might be useful as the anticancer therapies for ESCC.

\section{REFERENCES}

Beck K, Hunter I, Engel J (1990) Structure and function of laminin: anatomy of a multidomainglycoprotein. FASEB J 4: 148-160

Cantley LC (2002) The phosphoinositide 3-kinase pathway. Science 296: $1655-1657$

Carter WG, Kaur P, Gil SG, Gahr PJ, Wayner EA (1990) Distinct functions for integrins alpha3 beta1 in focal adhesions and alpha6 beta4/bullous pemphigoid antigen in a new stable anchoring contact (SAC) of keratinocytes: relation to hemidesmosomes. J Cell Biol 111: 3141-3154

Carter WG, Ryan MC, Gahr PJ (1991) Epiligrin, a new adhesion ligand for integrin $\alpha 3 \beta 1$ in epithelial basement membranes. Cell 65: 599-619

Decline F, Rousselle P (2001) Keratinocyte migration requires alpha2beta1 integrin-mediated interaction with the laminin 5 gamma2 chain. J Cell Sci 114: $811-823$

Engle J (1992) Laminins and other strange proteins. Biochemistry 31: $10643-10651$

Enzinger PC, Mayer RJ (2003) Esophageal cancer. N Engl J Med 349: 2241 - 2252

Fresno Vara JA, Casado E, De Castro J, Cejas P, Belda-Iniesta C, GonzálezBarón M (2004) PI3K/Akt signalling pathway and cancer. Cancer Treat Rev 30: $193-204$
Fukai Y, Masuda N, Kato H, Fukuchi M, Miyazaki T, Nakajima M, Sohda M, Kuwano H, Nakajima T (2005) Correlation between Laminin-5 $\gamma_{2}$ chain and Epidermal growth factor receptor expression in esophageal squamous cell carcinomas. Oncology 69: 71-80

Guo W, Pylayeva Y, Pepe A, Yoshioka T, Muller WJ, Inghirami G, Gianocotti FG (2006) Beta 4 integrin amplifies ErbB2 signaling to promote mammary tumorgenesis. Cell 126: 489-502

Hamilton SR, Aaltonen LA (2000) World Health Organization classification of tumours. Tumours of the Digestive System. Lyon: IARC Press

Kariya Y, Miyazaki K (2004) The basement membrane protein laminin-5 acts soluble cell motility factor. Exp Cell Res 297: 508-520

Koshikawa N, Moriyama K, Takamura H, Mizushima H, Nagashima Y, Yanoma S, Miyazaki K (1999) Overexpression of laminin $\gamma 2$-chain monomer in invading gastric carcinoma cells. Cancer Res 59: $5596-5601$

Luo J, Manning BD, Cantley LC (2003) Targeting the PI3K - Akt pathway in human cancer: rationale and promise. Cancer Cell 4: 257-262

Marinkovich MP (2007) Laminin 332 in squamous-cell carcinoma. Nature Rev Cancer 7: $370-380$ 
Matta M, Soini Y, Paakko P, Salo S, Tryggvason K, Autio-Harmainen H (1999) Expression of the laminin $\gamma 2$ chain in different histological types of lung carcinoma. A study of immunohistochemistry and in situ hybridization. J Pathol 188: $361-368$

Miyazaki K (2006) Laminin-5 (laminin-332) Unique biological activity and role in tumor growth and invasion. Cancer Sci 97: $91-98$

Miyazaki K, Kikkawa Y, Nakamura A, Yasumitsu H, Umeda M (1993) A large cell-adhesive scatter factor secreted by human gastric carcinoma cells. Proc Natl Acad Sci USA 90: 508-520

Nguyen BP, Gil SG, Carter WG (2000) Deposition of laminin 5 by keratinocytes regulates integrin adhesion and signaling. J Biol Chem 275: 31896-31907

Nikolopoulos SN, Blaikie P, Yoshioka T, Guo W, Puri C, Tacchetti C, Giancotti FG (2005) Targeted deletion of the integrin beta4 signaling domain suppresses laminin-5-dependent nuclear entry of mitogenactivated protein kinases and NF-kappaB, causing defects in epidermal growth and migration. Mol Cell Biol 25: 6090-6102

Ono Y, Nakanishi Y, Ino Y, Niki T, Yamada T, Yoshimura K, Saikawa M, Nakajima T, Hirohashi S (1999) Clinicopathologic significance of laminin $\gamma 2$ chain in squamous cell carcinoma of the tangue: immunohistochamical analysis of 67 lesions. Cancer 85: 2315-2321

Pyke C, Salo S, Ralfikiaer E, Romer J, Dano K, Tryggvason K (1995) Laminin5 is a marker of invading cancer cells in some human carcinomas and its coexpressed with the receptor for urokinase plasminogen activator in budding cancer cells in colon adenocarcinomas. Cancer Res 55: 4132-4139

Rousselle P, Lunstrum GP, Keene DR, Burgeson RE (1991) Kalinin: an epithelium-specific basement membrane adhesion molecule that is a component of anchoring filaments. J Cell Biol 114: 567-576
Ryan MC, Christiano AM, Enqvall E, Wewer UM, Miner JH, Sanes JR, Burqeson RE (1996) The functions of laminins: lessons from in vivo studies. Matrix Biol 15: 369-381

Schenk S, Hintermann E, Bilban M, Koshikawa N, Hojilla C, Khokha R, Quaranta V (2003) Binding to EGF receptor of a laminin-5 EGF-like fragment liberated during MMP-dependent mammary gland involution. J Cell Biol 161: 197-209

Sobin LH, Wittekind Ch (2002) TNM classification of malignant tumors, 6th ed New York: John Wiley\&Sons Inc

Soini Y, Maatta M, Salo S, Tryggvason K, Autio-Harmainen H (1996) Expression of laminin $\gamma 2$ chain in pancreatic adenocarcinoma. J Pathol 180: $290-294$

Timpl R (1989) Structure and biological activity of basement membrane proteins. Eur J Biochem 180: $487-502$

Vivanco J, Sawyers CL (2002) The phosphatidylinositol 3-Kinase AKT pathway in human cancer. Nat Rev Cancer 2: 489-501

Waterman EA, Sakai N, Nguyen NT, Horst BA, Veitch DP, Dev CN, Ortiz-Urda S, Khavari PA, Marinkovich MP (2007) A laminincollagen complex drives human epidermal carcinogenesis through phosphoinositol-3-kinase activation. Cancer Res 67: $4264-$ 4270

Yamamoto H, Itoh F, Iku S, Hosokawa M, Imai K (2001) Expression of the $\gamma 2$ chain of laminin- 5 at the invasive front is associated with recurrence and poor prognosis in human esophageal squamous cell carcinoma. Clin Cancer Res 7: 896-900

Yurchenco PD, Schittny JC (1990) Molecular architecture of basement membranes. FASEB J 4: $1577-1590$ 